\title{
Coping Resources for Persons With Traumatic Spinal Cord Injury in A Tanzania Rural Area
}

\author{
Haleluya Moshi ${ }^{1,2}$, Gunnevi Sundelin ${ }^{1}$, Klas-Göran Sahlen ${ }^{3,4}$ Rhoda Anthea $^{5}$ \& Ann Sörlin ${ }^{1}$. \\ ${ }^{1}$ Department of Community Medicine and Rehabilitation, Physiotherapy, Umeå University, Umeå, Sweden \\ ${ }^{2}$ Kilimanjaro Cristian Medical University College, Moshi, Tanzania \\ ${ }^{3}$ Department of Public Health and Clinical Medicine, Epidemiology and Global Health, Umeå University, Umeå, \\ Sweden \\ ${ }^{4}$ Department of Nursing, Umeå University, Umeå, Sweden \\ ${ }^{5}$ The Faculty of Community and Health Sciences University of Western Cape, Western cape, South Africa \\ Correspondence: Haleluya Moshi Kilimanjaro, Cristian Medical University College, P. O. Box 3010, Moshi, \\ Tanzania. Tel: 255-75-502-9640. E-mail: luluwayesu@mail.com
}

Received: February 7, 2018 Accepted: April 10, 2018 Online Published: April 19, 2018

doi:10.5539/gjhs.v10n5p138 URL: https://doi.org/10.5539/gjhs.v10n5p138

\begin{abstract}
Background: Persons with traumatic spinal cord injury (TSCI) in Tanzanian rural settings face a variety of geographical and socioeconomic challenges that make life almost impossible for them. However, some have managed to live relatively long lives despite these difficult conditions. This study aimed at exploring secrets behind successful lives of persons with TSCI in typical resource-constrained rural Tanzanian settings.
\end{abstract}

Methods: A modified constructivist grounded theory was employed for the analysis of data from 10 individuals who have lived between 7 and 28 years with TSCI in typical Tanzanian rural area. The 10 were purposively selected from 15 interviews that were conducted in 2011. The analysis followed the constructivist approach in which data was first open and axial coded, prior to categories being constructed. The categories were frequently reviewed in light of the available literature to determine the over-arching core category that described or connected the rest.

Results: Nine categories (identified as internal and external coping resources) were constructed. The internal coping resources were: secured in God, increase in awareness on health risk, problem-solving skills and social skills. External coping resources were: having a reliable family, varying support from the community, a matter of possession and left without means for mobility. Acceptance was later identified as a core category that determines identification and utilization of the rest of the coping resources.

Conclusion: Persons with traumatic spinal cord injury can survive for a relatively long time despite the hostile environment. Coping with these environments requires the employment of various coping resources, acceptance being the most important.

Keywords: acceptance, coping resources, rehabilitation, rural area, spinal cord injury.

\section{Introduction}

Traumatic spinal cord injury (TSCI) is an unprepared event that leads to partial or full loss of sensory and/or motor functions, as well as autonomic dysfunction dependent on the affected spinal level (Biering-Sorensen, Bickenbach, El Masry, Officer, \& von Groote, 2011). Immobility and future consequences such as recurrent SCI-related health complications, inability to pursue education and career, and failure to participate in the community leads to a sequence of biopsychosocial and economic struggles throughout life (Biering-Sorensen et al., 2011; DeRoon-Cassini, de St Aubin, Valvano, Hastings, \& Brasel, 2013; Franzblau \& Chung, 2015). While in this state, individuals with SCI require healthcare and rehabilitation services to sustain their health and minimize risk for ill- health and death (Middleton et al., 2012; Oderud, 2014). For these reasons, even with the best rehabilitation and healthcare services, life expectancy for persons with TSCI is relatively low compared to that of the general population (Biering-Sorensen et al., 2011; Ridler, 2017). 
Mobility and other impairment that results from SCI creates a need for assistance in varying degrees to accomplish activities necessary for daily living and inclusion into the community. In poor, rural African settings, such assistance is normally provided by a spouse, family member or close relative. Various studies have shown that social support is a key facilitator of daily activities, mobility and overall quality of life for persons with SCI regardless of context (Arya et al., 2016; Khanjani, Younesi, Khankeh, \& Azkhosh, 2017). Furthermore, support from close relatives and friends contributes to resilience, better physical and mental health, reduced pain, better coping, and greater satisfaction with life among persons with SCI (Bailey, Gammage, Ingen, \& Ditor, 2015; Muller, Peter, Cieza, \& Geyh, 2012; Muller et al., 2015; Zsoldos, Satori, \& Zana, 2014). However, the attainment of such support depends on context and cultural values, as well as on the individual's ability to create and utilize social networks (Guilcher et al., 2012; Muller et al., 2012).

Assistive devices are of paramount importance to persons with SCI, particularly in self-care, bladder management and mobility. Improper bladder emptying has also been reported to cause massive damage to the kidneys following urine reflux as a result of bladder stone formation (Bartel, Krebs, Wollner, Gocking, \& Pannek, 2014). Persons with TSCI in low-income countries such as Tanzania face unavailability and unaffordability of bladder management devices as well as appropriate wheelchairs (Oderud, 2014; WHO, ISPO, \& USAID, 2008b) Consequently, unsafe bladder-emptying methods have led to increased prevalence of urinary tract infections in poor settings (Oderud, 2014; Salameh, Mohajer, \& Daroucihe, 2015). Having access to an appropriate wheelchair is a pre requisite for mobility, posture and function for a person with traumatic SCI. Wheelchair unavailability or unaffordability accounts for most resource-constrained settings' dependency on inappropriate donated wheelchairs from wealthier countries. Inappropriate wheelchair coupled with wheelchair-restrictive environment are some of the major barriers to mobility and inclusion into the community for tis population (WHO et al., 2008b). Unavailability and unaffordability of the assistive devices account for immobility and disengagement in educational opportunities and meaningful occupations or careers (Oderud, 2014; Reinhardt et al., 2016).

Disengagement in educational and income-generating activities describes the reported high levels of unemployment among persons with SCI compared to controls (Blauwet et al., 2013). Several employment benefits for a person with spinal cord injury have been identified, such as earning an income, connecting with the broader external world, feeling valued and useful to the community and attaining various social security benefits, including health insurance (Meade, Reed, Saunders, \& Krause, 2015). Tone Øderud (2014) points to unemployment as the root cause of financial insufficiency for persons with SCI, which results in the inability to afford basic needs, including rehabilitation devices (Oderud, 2014). Unemployed persons with TSCI are more likely to develop anxiety and depression as compared to those who are employed (Hwang, Zebracki, Chlan, \& Vogel, 2014). The majority of persons with TSCI in the rural lower-income countries were peasant farmers or those involved in a small-scale business at the time of injury. Considering the working environments of the informal sector in African rural settings, it would be very difficult for such people to return to their former economic activities in a wheelchair (Burns \& O'Connell, 2012). For these reasons, the majority of persons with TSCI would opt to create subsidiary income-generating activities within their homes. Moreover, difficulties in self-employment in low-income countries are hard to overcome due to a lack of capital and market, poor infrastructure, and lack of entrepreneurship skills (Oderud, 2014). Boylan and Burchardt (2002) present some important case studies featuring persons with spinal cord injury who had to overcome a series of challenges in regaining employment within their communities.

As is typical elsewhere in developing countries, Tanzanian rural settings are not designed to meet the physical, psychosocial and economic needs of persons with SCI (Burns \& O'Connell, 2012; MacLachlan \& Mannan, 2014). For example, most public roads, buildings and homes are not wheelchair accessible. Additionally, space in the house, living and washrooms do not favor the mobility nor allow for the functions of a wheelchair user while inside the house (MacLachlan \& Mannan, 2014). Beds and pressure relief mattresses for the prevention of pressure ulcers may not be available and afforded by the majority. Rehabilitation services are rare within these communities, and in the cases of the few that are available, it is hard to access and afford them. The unavailability of health and rehabilitation services and devices coupled with inaccessible environment makes life nearly impossible for persons with TSCI in the rural settings (MacLachlan \& Mannan, 2014). This partly explains the reported relatively lower life expectancy among persons with TSCI in low-income countries compared to those in more developed settings (Oderud, 2014).

Uniquely, there are persons with traumatic spinal cord injury who have managed to live in these adverse conditions for a relatively long time. Little is documented about their lives and whether anything can be learned 
from them to enhance the lives of others bearing similar characteristics within communities. Their life experiences could provide clues as to what could improve life for those with SCI in resource-constrained and inaccessible environments. The aim of this study was to thoroughly assess the strategies used by persons with TSCI in these resource constrained environment to address their needs hence making life possible.

\section{Methods}

\subsection{Characteristics of the Participants}

\subsubsection{Area Description}

In qualitative research the description of area where the interview took place is paramount due to the fact that the lived experience is socially constructed (Knapp, 2016). The Kilimanjaro region is located in a part of northeastern Tanzania that borders with Kenya. Tree climbing in search for cattle feed, fruit and firewood is a common practice especially among male members of the family. For this reason men often sustain TSCIs after falling from trees. Women are more involved in head loading, as they frequently carry grass for cow feed as well as firewood, water and farm produce, to either home or market. Falling with such loads on their heads is a common cause of TSCIs for women in these settings.

The settings are noted for roads that are inaccessible to wheelchair users, scarce community-based health and rehabilitation services, and relatively low socioeconomic status. The combination of inaccessibility for wheelchairs and low socioeconomic status has meant that persons who have been discharged after hospitalization with TSCIs face serious difficulties with mobility and inclusion in daily life. Furthermore, prevailing complications such as pressure ulcers, respiratory and urinary tract infections are usual cause for mortality in and after discharge from hospital. However, a few people have uniquely adapted to these restrictive environments and lived longer than had been anticipated.

\subsubsection{Sampling Procedure and Sample Size}

In 2011, in-depth interviews were conducted in the homes of 15 persons with TSCI to determine their quality of life. Part of the analysis was conducted for masters thesis, leaving a significantly large material unanalyzed. Two researchers reviewed the interview materials and noted that some of the interviewed persons had lived long beyond the time predicted in the literature (Burns \& O'Connell, 2012). This inspired the researchers to approach the interview materials again by using a modified grounded theory approach for analysis. The intention of the second analysis was to explore (more inductively) what it takes to live with TSCI in resource-constrained rural settings. Out of the 15 interviews, 10 were purposively selected based on the subjects having lived for the longest time with SCI. Their ages ranged from 26 to 60, and they had lived with SCI for between 7 and 28 years. Their demographic characteristics were diverse, as shown in Table 1.

Due to lack of addresses and database for persons with spinal cord injury in this region, the first three participants were obtained from the Kilimanjaro Association for the Spinally Injured (KASI) then snowballing was used to identify subsequent eligible subject(s). 
Table 1. Sociodemographic characteristics of the participants

\begin{tabular}{llllllll}
\hline Pseudonym & Sex & $\begin{array}{l}\text { Current } \\
\text { (years) }\end{array}$ & $\begin{array}{l}\text { age } \\
\text { injury } \\
\text { (years) }\end{array}$ & $\begin{array}{c}\text { at } \\
\text { Time since } \\
\text { injury (years) }\end{array}$ & $\begin{array}{l}\text { Level } \\
\text { impaired }\end{array}$ & $\begin{array}{l}\text { Level } \\
\text { education }\end{array}$ & Engagement in economic activity \\
\hline P1 & Female & 40 & 20 & 20 & Para & Primary & $\begin{array}{l}\text { Self-employed (small retail shop at } \\
\text { home) }\end{array}$ \\
P2 & Male & 29 & 22 & 7 & Tetra & Primary & No significant economic activity \\
P3 & Female & 45 & 24 & 21 & Para & Primary & No significant economic activity \\
P4 & Male & 37 & 27 & 10 & Para & Primary & Beggar \\
P5 & Male & 43 & 35 & 8 & Para & Primary & No significant economic activity \\
P6 & Male & 40 & 30 & 10 & Para & Primary & Self-employed (cycle repair at home) \\
P7 & Male & 60 & 32 & 28 & Tetra & College & No significant economic activity \\
P8 & Male & 38 & 28 & 10 & Tetra & Primary & No significant economic activity \\
P9 & Male & 42 & 31 & 11 & Para & Primary & Self-employed (embroidery at home) \\
P10 & Female & 61 & 45 & 16 & Para & Primary & No significant economic activity \\
\hline
\end{tabular}

\section{Key:}

Primary is the lowest level of formal education in Tanzania

Para (paraplegia) means paralysis affecting lower limbs only

Tetra (tetraplegia) means paralysis affecting all upper and lower limbs

\subsection{Data Collection}

Data had already been collected by in-depth interviews that took place in the homes of fifteen purposively selected participants. After each interview, the researcher read a summary of the key points to the participant for confirmation and wrote down various memos and summaries of the main findings. These memos and interview summaries were stored together with the interview scripts after the first analysis in 2012. The following are two examples of memos written after the fourth and seventh interviews.

Memo after $4^{\text {th }}$ interview: There is a clear connection between interview 3 and today's. We gathered that that environment is the major barrier to engagement into social and economic activities. We ourselves struggled to walk through the path leading to the home of the previous participant P3.

P4 is another evidence of environmental barriers as he left village and moved closer to town so that "he can propel his wheelchair on better roads". He is also an example of the importance of having a family because he says that there are several moments he get stranded, sick or needing physical help but there is no one to help. He looks unhealthy, unhappy and....neglected. So far he is the only one who informed us that he is a beggar. He seems like someone who has lost control over his life.

Memo after $7^{\text {th }}$ interview: It really matters if someone had a spouse and a carrier at the time of injury. These seem to be the capital that one uses to move on with life. P7 counts it lucky that he was married and some of his children grown up but also that he had bought a property (land). Having capital at the time of injury gives you some control over certain economic situations. Belief in God brings meaning to life even when all limbs are paralyzed. P7 is the oldest of all participants in this study, he speaks of self and of other persons who got injured after him and died of various SCI related complications because he had been a leader in an organization of persons with traumatic SCI. Today's interview was richer than the first few ones.

The summary of findings was written after each interview as a preliminary analysis (Strauss \& Corbin, 1998) and (together with memos) helped in refining the questions for subsequent interviews. For example, the family began emerging as a strong concept during the first three interviews; therefore, in subsequent interviews this was 
explored more deeply. However, the interviewer remained flexible to allow subsequent participants to introduced new concepts to the interview. During the interviews, some notes on important occurrences involving the patient and the family (e.g. emotions, visitor(s) walking) were recorded in a notebook. An example of this is illustrated in the interview summary for P6.

Summary 6: When we arrived at P6's home there was nobody in the house and there are chicken in small dens outside his house. There also tools for puncture repairs for bicycle wheels. His neighbors came to ask us what we wanted....they told us to look for him in the church. We found P6 in the church at 11:30 am, about $1 / 2$ kilometer over a bad road from his home even though it is not a "church day". He says he comes here to pray as often as possible. He believes that if God does not make him walk again he will look after him. He plans to get married because he says living alone has been very difficult all these years. There is excitement in his face whenever he talks of the things he has achieved despite the disability. P6 believes his achievements are made possible by God and people who care. He needs a family of his own so he is planning to get married. He frequently mentions an organization that supports persons with disability as being the most helpful. One thing is obvious; God is the center of his life. He mentions people who supported him in almost every sentence he utters. As we accompanied him to his home, some sections of the road were so restrictive that he needed people to push him although he is one of the fittest persons with TSCI in the region. What is encouraging is that there are always people around who are willing to help, even without being asked. Once again we feel that one needs a family but also other people in the community.

\subsection{Data Analysis}

In this analysis, a modified constructivist grounded theory approach based on Corbin and Straus (Corbin \& Strauss, 2008) was employed. A classical constructivist approach requires that in-depth interviews be conducted by starting from a very broad perspective before subsequently narrowing the focus and refining inquiry based on the emerging concepts (Charmaz, 2008). Identification of the emerging concepts that require further elaboration in subsequent interviews is achieved through simultaneous data collection and analysis (Charmaz, 2008; Corbin \& Strauss, 2008; Mills, Bonner, \& Francis, 2006). However, in this study this method was modified, as the analyzed interview transcripts had been conducted some years before. Still, the stored memos and summaries served the purpose of retrospective recalling of events. The four necessary steps in constructivist analysis (open coding, axial coding, category formation and identification of a core category) were followed.

\subsubsection{Open Coding}

Coding was conducted using computer software called Open Code (Mustonen, 2013), which enabled for coding without providing any interpretation in the first phase (synthesis I). The axial codes were read several times (simultaneous with the review of the memos) for further conceptualization that would allow for formation of categories (Corbin \& Strauss, 2008; Glaser, 2002). The coding process began with two researchers coding the first two interview scripts, then agreeing on the codes and building a common understanding behind "open coding." In order to avoid a pre-conceived hypothesis (Charmaz, 2008), the interviews were open-coded at the most abstract level. Abstraction was also a means through which the researcher could remain as close as possible to the data, which is one of the core virtues of grounded theory (Glaser, 2002). The researchers used the Open Code 4.03 computer software for this task. During open coding, the researchers were as open as possible to the scripts so that new insights might emerge from the data. A code was assigned to a sentence, a phrase, or an in vivo code which is a word or phrase as obtained from the original script.|

\subsubsection{Axial Coding and Categorization}

After open coding, the codes were reviewed several times, and those that could be assembled to form a more meaningful code were dissolved to form an axial code (synthesis II). The codes were read through several times and those that pointed to a particular process or event were grouped as part of a more inclusive code (Strauss \& Corbin, 1998). At this level, several axial codes were constructed. The codes were frequently reviewed to assess their relationship to each other, and in so doing some were combined to form a more inclusive code or a category (Charmaz, 2008). Categories were formed (synthesis III) after repeatedly reading the axial codes and the memos in a reflective manner. The two tables below partly illustrate the construction of categories "Hope and believing the indescribable God" and "acceptance". 
Table 2. Example of analysis in construction of the category "Acceptance"

\begin{tabular}{lll}
\hline Codes & Axial Codes & Category \\
\hline $\begin{array}{l}\text { accepting your health condition }+ \text { accept the } \\
\text { outcomes }+ \text { acceptance by the community is crucial }\end{array}$ & Coming to terms with disability & Acceptance \\
+Offer something to be accepted + What is done is & Let things take their natural course & Accept and be accepted \\
done + Move on with life + spouse who do not care & Ace & \\
cannot accept + Feeling accepted + settle with new & Accept what cannot be changed & \\
means + I am very accepted! +neighbors accept me & & \\
\hline
\end{tabular}

\subsubsection{Identification of the Core Category and Theory Construction}

The relationship between the categories was sought repeatedly (simultaneously with the literature review) in order to construe a core category. Literature review was done after the formation of the categories to avoid theorizing based on the literature rather than on the interviews (Corbin \& Strauss, 2008). At first the categories were conceived as coping strategies from various literature reviews. However, when reading the book "Stress Appraisal and Coping" by Lazarus and Folkman (1984), it was recognized that the formed categories were "coping resources" rather than "coping strategies". Three researchers discussed this and agreed that these were "resources" rather than "strategies".

After several readings of the categories, memos, interview summaries and literature review inductively (Charmaz, 2008; Corbin \& Strauss, 2008), we found that the first three categories demonstrated dominance over others. These were: secured in God, social support and accepting what cannot be changed. We tested each category with the questions "What is happening?" "What is explaining what?" "Why is....happening" and "What does it take for ....to happen?" Although many works of literature noted these three coping resources, we drafted models pertaining to each and found "acceptance" to be the core category. This category was also arrived at largely through the memos and interview summaries. For example, we noted that words like "accept what cannot be changed" and "I am very accepted" and "people must accept you" and "you should love yourself" frequently appeared in the codes, memos and interview summaries. Accepting self and being accepted by social and physical environments described the identification and utilization of the rest of the coping resources. A model was constructed to show the position of acceptance in identification and utilization of coping resources and its relationship with the rest of the resources, as shown in figures $1 \mathrm{a}$ and $1 \mathrm{~b}$.

\section{Results}

Nine categories from the analysis and they were identified as "coping resources for a person with SCI". For conceptualization purposes, these categories were grouped into "internal" and "external" coping resources.

\subsection{Internal Coping Resources}

\subsubsection{Secured in God}

While talking of their lives, participants repeatedly mentioned that God is the one they trusted and that he is the one who could help them. There were several pictures of God in our participants' descriptions. God was someone who knew that this would happen, who had spared their lives, and who would empower participants' lives and see to their safety.

God is my security. I have given him all my life because you will find that here in the village...so many things are heart breaking, do you hear?...that is why I told you that even sometimes if I am coming from church service I come back home straight away for the sake of my safety. For that I thank God, I am not worried about my security. - P4

\subsubsection{Increase in Awareness on Health Risk}

Persons with spinal cord injuries have multiple organ impairments. The skin, musculoskeletal, urinary and cardiovascular systems are all affected. In this category, participants repeatedly stressed that one has to be careful about health and prevent the self from complications such as pressure ulcers, contractures, urinary tract infections and secondary injuries, knowing that health and energy are important coping resources.

I am very careful about sores [pressure ulcers]....Yea, to be careful about sores, that is what I think about in my body... You know in this state if you get a sore you won't understand that you have got one 
- P3.

It is for this reason that all participants felt that they needed continuous health check-ups even though it was difficult to do this due to poor economic conditions and inaccessible public transportation and environmental issues. P9 has continuous neuropathic pain, which he can hardly do anything about, and he is worried about his fate:

This body now... what worries me is the pain inside. I don't know with the lungs or what, and the way this part of chest pains me from the spirit [heart] continues to the kidneys...that is what worries me, it will just finish me!

\subsubsection{Problem-Solving Skills}

Persons with TSCI have to demonstrate a variety of mental and physical abilities if they are to solve the problems they are confronted with throughout the day. To find alternatives to inaccessible health and rehabilitation services, to improvise rehabilitation instruments such as modification of the sex condoms as uridome, and to use available rubber and wood materials to replace broken caster wheels for their wheelchairs. For most participants, establishing and running a small income-generating activity was just as important as budgeting carefully the profit that was obtained:

...I manage life because I sell airtime [recharge phones]. I sell airtime and whatever I get there even if it is little, I can budget it... I have, like five chicken there. I had a project of keeping pigs but failed because I did not get that support of someone cleaning their house and feeding them - P8

\subsubsection{Social Skills}

Social skills were frequently expressed as one of the important virtues for the attainment of support for daily needs. Although social support was available, it was the person with the disability who had to ponder on its gainful utilization. For example, due to environmental and financial insufficiency, P3 has to find alternative to access health services, as she discloses here:

When I feel that am sick I can just write a piece of paper [explaining signs and symptoms] to be taken to the nearby health center so that in any way they can send some medications for me. So I take those medications without any prior investigations...that worry me so much...because I do not have that financial ability to go to the hospital.

\subsection{External Coping Resources}

Social support was one of the largest categories in terms of the number of codes forming it. The codes that formed this category were reviewed several times and formed two discrete categories: family (nuclear and extended) and community (including charity and faith-based organizations), and these two had to be viewed differently. It was from this conceptualization where having a reliable family and varying support from the community formed the two categories.

\subsubsection{Having a Reliable Family}

Participants indicated that they had to selectively create meaningful social networks with people within and outside the family, but also had to develop problem-solving skills. The spouse and the family were reported to be the most reliable psychosocial and economic supporters. When a married individual suffers TSCI, the spouse should take on the responsibility of looking after the family. P8 contends that family support is the only support that is guaranteed.

After getting injured, many friends ran away...yes, but I thank God that family are the people that I thank so much because they really have made great efforts for me for sure.

Due to the restrictive environment, if the PWSI falls sick, it is the spouse who visits the health facility and explains the symptoms to the clinicians who would prescribe medication based on the spouse's explanation. P9's wife explains what she does:

...You know we just guess. You [the wife] go to the hospital, you explain to the doctor the way he is feeling sick, the doctor takes your word and writes medication [prescribes] for him.

As for the children, there was a twofold distinction. The older, mature and economically independent children provide significant support to a parent with TSCI. On the contrary, little children were viewed as a reason for dissatisfaction, inner pain and worries, as the person with TSCI felt that provision for the children was jeopardized and their dreams shattered. A mother of five, with the youngest being conceived post injury, describes her feelings 
as:

I look at the family, then I look at the house and the children are now growing up, in this small house, then I say if it was that time when I was walking I would have joined forces with my husband so we would have added at least two more room for these children because they are grown up. But now we are failing to do that. When I look to this my head gets piled with thoughts even more....yes.

In the African context, relatives such as brothers and sisters, cousins and nephews, uncles and aunts can serve as one's immediate family in some circumstances. Where such relatives are present and supportive, participants reported a bearable life. Those who did not have family support at any point reported on this as being a very difficult condition. P9 has been affected by loneliness to the extent that he perceives himself very negatively. This is how he views himself when his wife (who is his only companion) leaves the house to search for household needs:

Thoughts that come to me when I am left alone are that, I am not a human being anymore. I am only here doing...pain and counting banana leaves, no one to talk to. I become very bad luck, there is no way of talking to people.

\subsubsection{Varying Support From the Community}

Moving outside the family circle and into the community, support from others was noted and discussed. The importance of relating well with neighbours, peers, the church, organizations for disabled people, and health and rehabilitation professionals is very important for life in rural areas. However, this connection with people outside the family demands an ability to know whose advice and support is useful. For example, friends may disappear over time, and the community may perceive people with TSCI differently, which on some occasions causes insecurity. In this case the person with TSCI has to have the skills to selectively form positive connections with the community and avoid negative ones.

The most reliable social support outside the family is neighbouring children. P2 is a C5 quadriplegic who needs total assistance with self-care. The neighbouring children are described as being important:

I mean like this boy here (he points at a boy about 5 meters away)...these...these young boys are the ones who help me...... or...or my friends who give me different types of support... I mean...they wash me, they sleep with me in the room, they get me out...I mean if you...you remove that life for me will be very difficult.

Throughout the interviews, the interviewees acknowledged assistance from either organizations for disabled people or faith-based organizations in terms of mobility and bladder care aids, beddings and for housing. Sadly, it was repeatedly indicated that such support was unreliable, as it depended on donations from abroad.

These organizations of persons with disabilities have helped me a lot! Together with this church department which evolved for people who are living in difficult environment although they don't often visit us, but most of the time they were helping me because of medication, sores, they were personally bringing a nurse to treat me here so they helped me with so many things - P6.

\subsubsection{A Matter of Possessions}

In this category, it was observed that the position the person holds and their possessions at the time of injury matter. Education, independent family members, paying occupations, disability compensation and having an asset when the injury occurred were described as being some of the most important coping and life-sustaining resources. Those who had acquired education or certain skills indicated that they could use their previously attained skills if they were empowered and their surroundings were accessible to them.Getting injured while one is educated and as a stable job is almost a guarantee that one will manage life. One of the participants with tetraplegia had lived successfully with this condition for more than 28 years, and he says this is one of many things that made him manage his life with a disability:

First it was fortunate that I had a job before and I had already developed a vision for my life. But more good luck was that my wife had a job as well.

Owning property (normally, an inheritable piece of land) was mentioned in all interviews as an important facilitator of life. As one informant, a widow, described the importance of a piece of land:

I sold bananas to people who used to visit me so I used them [money] slowly and carefully because when I am at home like this I do not have to buy vegetables [they grow wildly in the farm] - P10 


\subsubsection{Left Out Without Mobility Device}

Environment and wheelchair formed a very crucial category, as all informants indicated that mobility was a crucial part of their lives. They need to get to the community for various meaningful occasions such as village meetings, worship services and involvement in small income-generating activities. During the interviews, a clear pattern emerged in which the functioning and mobility of the individual is dependent upon the environment and a wheelchair. Wheelchairs are unaffordable and inaccessible to the majority. The wheelchairs that were available were inappropriate either for the type of disability or for functionality in rural settings.

...so you can see that the first wheelchair which I bought for myself [28 years ago] is the one that I am using to date. Recently my son went to Sweden and I asked him to try to find another one for me from there but he said wheelchairs there are very expensive and secondly they are not made to suit this environment. $-\mathrm{P} 7$

Some cases are astonishing. One man who was injured 10 years ago has never been away from his home surroundings due to the environment being inaccessible. He lives on top of a hill where even able-bodied individuals struggle to reach the house. On the day of his hospital discharge, six strong men from the village carried him and his wheelchair separately from the main road to his house. This is the only established home where he could return after the injury, and it is where his parents, wife and son live.

From this environment here? It is only a radio that I listen to! For example, yesterday in the neighbourhood there was confirmation. I stayed home the whole day! The problem is the bad roads. - P5

\subsection{Accepting self and being accepted as the core category}

Acceptance was recognized as being the driving force behind the rest of the categories throughout. It was a key not only to survival but also to utilization of the available coping and life-sustaining resources. First, the individual must accept the resulting permanent impairment in order to direct attention into seeking social and physical support. Secondly, the community and physical environment must accept the person with TSCI in terms of offering needed accessibility, physical and moral support. P1 got injured when he was only 26 years old, and he now talks of his transformation:

In the beginning I used to have very negative thoughts to an extent of wishing that this body should be cut and thrown away... or just lose it! But for now I really care for this body because I know I can live a life pleasing to God! Now I take this body that it is my body altogether even though it is "cracked" still I take it as my body! - P1

Another participant (P3) describes her total acceptance of the condition, but also her acceptance of God's plan for this situation:

...it is only God who is carrying me through. And I have come to terms with this condition; I have accepted it and see it as a normal condition. I now see myself living life like other people. Yea, so come anything, I accept it.

It also follows that faith in God is a sign of accepting that he is omnipotent, all-knowing, and determines the fate of each human being. Furthermore, one has to develop social skills for acceptance in the immediate and distant social circle. One has to accept the environment, whether it is accessible or not, as s/he may spend the rest of their life here. This will help the individual to avoid daily regrets and to feeling dissatisfied with life, which may lead to depression. P5 lives in a very restrictive environment, but he has come to terms with this:

I am already used to my home environment despite the difficulties...

Acceptance cultivates faith in God, unifies the family, connects the individual with the community and enables life in an inaccessible environment. One must "have" a reliable family, a supportive social network, have attained assets (capital) and have a mobility aid within an accessible environment. Such a person must also "be able to" accept the condition, believe in God, associate well with other people, have a good social position, have control over the resources at hand, and mediate/negotiate where control is impossible. We argue that no matter how many coping resources are available for the individual, if there is no acceptance or chance of being accepted such resources may not be realized and or utilized effectively. 


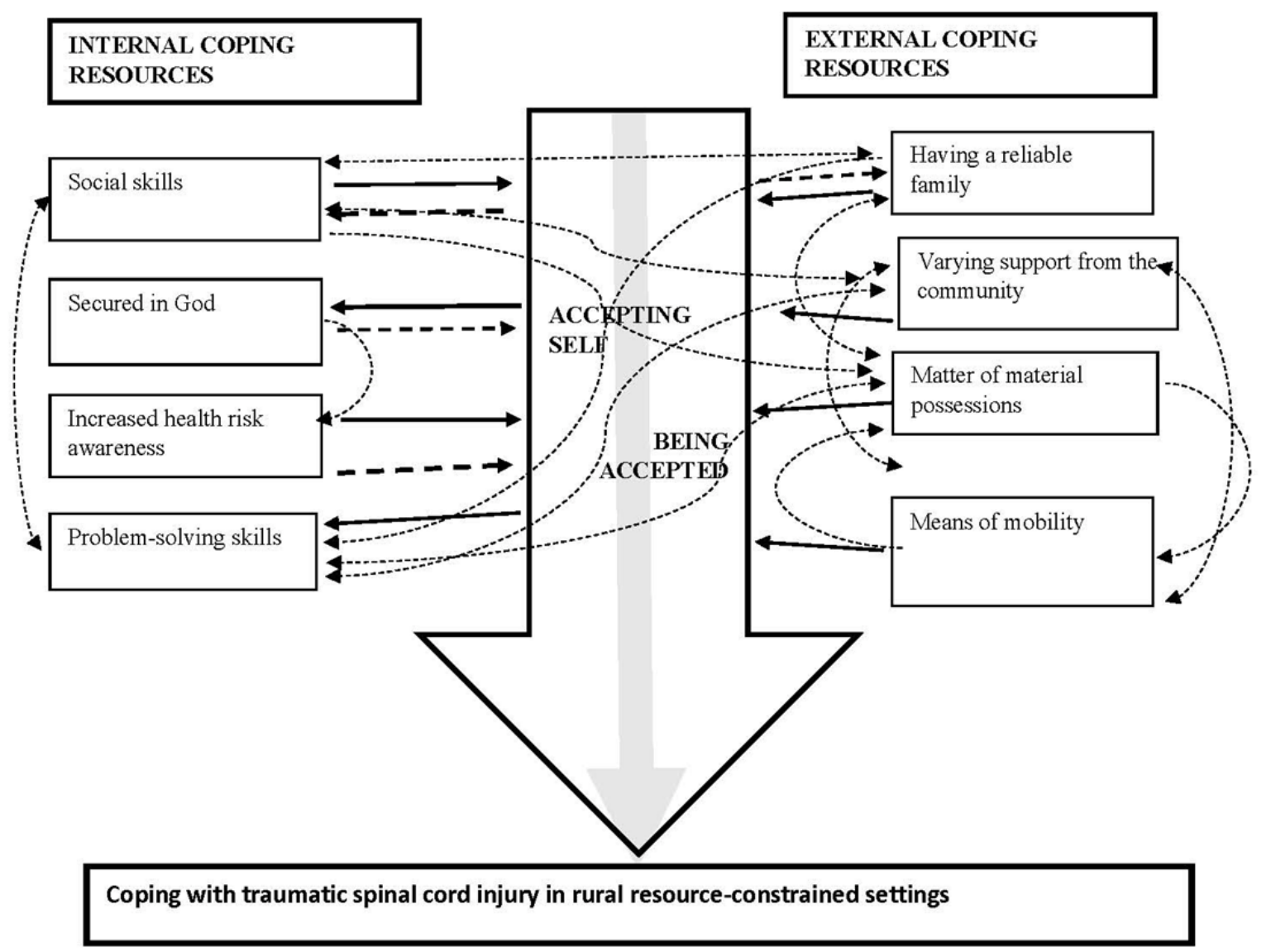

Figure 1a. A conceptual model of acceptance as a key to realization and utilization of coping resources for persons with TSCI in a resource-constrained rural setting

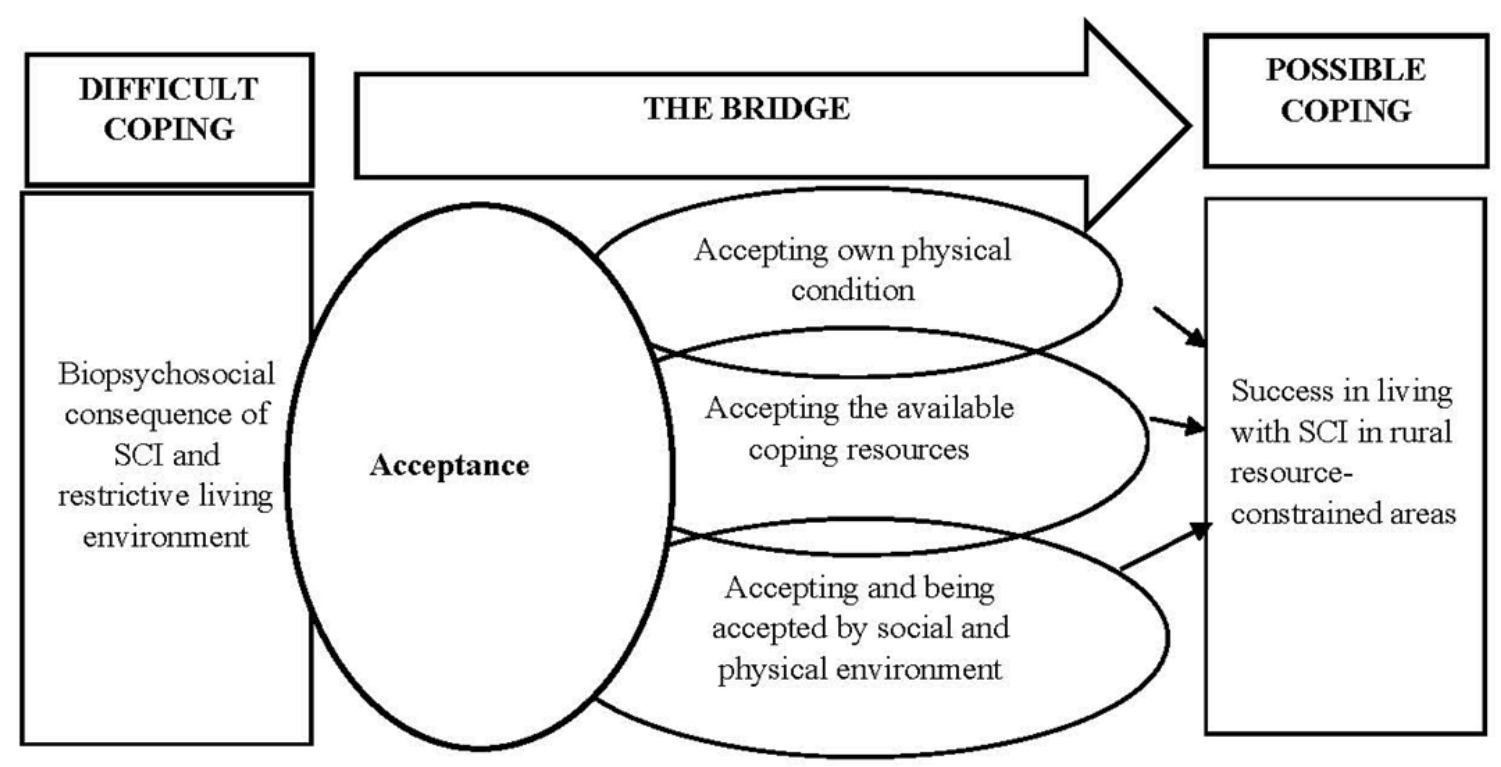

Figure 1b. A model focusing on acceptance as a bridge from difficulties to possibilities of coping with SCI in resource-constrained settings 


\section{Discussion}

According to Lazarus and Folkman (1984), coping success is determined by the available internal and external factors termed as "coping resources". Generally, coping resources include health and energy, positive beliefs, problem-solving skills, social skills, social support and material resources. Various studies have reported on the importance of coping resources on the psychosocial adaptation, re-adjustment and quality of life following a loss (Bailey et al., 2015).

Acceptance emerged as the core category, central to coping. As noted, this is a twofold acceptance: accepting self despite the impaired body, and being accepted by the social and physical environment in which one lives. On the other side of the coin, coping resources could either be the result or cause of acceptance. For example, it has been shown that where there is social support, the individual will most likely accept the condition. In the same manner, individuals who have accepted their health condition will most likely engage in life situations and practice social skills, and thus increase their chances of attaining social support (Muller et al., 2012; Muller et al., 2015).

The value of acceptance to successful coping and valuing self has also been stressed in previous studies (Bailey et al., 2015; Dibb, Ellis-Hill, Donovan-Hall, Burridge, \& Rushton, 2014). Acceptance has a positive effect on various aspects of the life of the individual with SCI and that partly explains its role in realization and utilization of the coping and life-sustaining resources. For example, acceptance has been associated with better mental health (van Leeuwen, Edelaar-Peeters, Peter, Stiggelbout, \& Post, 2015) psychological growth (Chuang, Yang, \& Kuo, 2015), facilitation of self-management (Munce et al., 2014), reduced vulnerability to depression (Kraft \& Dorstyn, 2015) and goal adjustment (Lankveld, Diemen, \& Nes, 2011). Looking at the widespread effect of acceptance on the various aspects of the individual with SCI, it is not surprising that it was found to be central to the realization and utilization of the rest of the coping and life-sustaining resources. This study indicates that it is not only accepting the disability that matters, but also that the individual should accept the available coping resources and also be accepted by the living environment. Martinez (2015) describes this as "self and life acceptance", and Alysse and colleagues (2015) posit acceptance as the root cause of stability, which in turn determines success in many other aspects of daily life (Bailey et al., 2015).

In this study, like other studies (Arya et al., 2016; Khanjani et al., 2017), social support from the family and members of the community is found to be one of the crucial coping resources for persons with TSCI. This could be explained by the fact that persons with TSCI need long-term emotional and physical support due to the physical abilities they have lost. This support could be even more needed by individuals in poor rural settings due to the fact that the environment in which they live is massively restrictive in terms of mobility, carrier and leisure persuasion. Having people to associate with and who may assist from time to time has shown to increase resilience, mental and physical wellbeing for persons with SCI (Muller et al., 2012; Muller et al., 2015). For this reason facilitating a good supportive relationship between the person with TSCI, the family and the community could lead to better rehabilitation outcomes. This goal will most likely be achieved if the individual accepts available support and is accepted by the people from whom the support is anticipated.

Accepting others and being accepted by them may not be a game of chance; rather, it is an outcome that may demand social skills from both sides. In this case the person has to make an effort to be acceptable to the community and accept the community as it is. As defined in Lazarus \& Folkman, (1984), a social skill is that which allows for mutual benefit of the relating parties. However, a person with TSCI in resource-constrained areas is more on the recipient side and may use this skill to achieve emotional, physical and even material/financial support. This skill could be of good yield if the person has created an adequate social network with socioeconomically potential individuals (Zinman et al., 2014) as it helps create acceptability by both parties. It is important that individuals who sustain TSCI in poverty stricken areas are facilitated in the utilization of skills to maximize gains from their social networks.

Problem-solving skills are also identified as an important coping resource for individuals living with TSCI in resource-constrained rural areas. Citing Janis and Mann (1977), Lazarus and Folkman (1984, p. 142) define problem-solving skills as "the ability to search for information, analyze situation for the purpose of identifying the problem in order to generate alternative courses of action, weigh the alternative course of action with respect to desired or anticipated outcomes, select and implement appropriate plan of action". Need for problem-solving skills for a person with SCI has also been emphasized in a study that was conducted in Switzerland by Nützi and colleagues (Nutzi, Trezzini, Ronca, \& Schwegler, 2017). As can be seen in this study, accepting self is a crucial bridge to realizing and applying one's problem-solving skills. In their book, Davidson and Sternberg (2003) report that problem solving was more feasible to persons with acceptance among other traits (Davidson \& Sternberg, 2003). 
The information-processing theory of human problem solving (Simon, 1977) indicates that the individual must first accept the task before considering employment of problem-solving skills in it. So accepting to engage despite impairment is the first and foremost important step that a person with TSCI should be assisted in making before considering inclusion and participation in life situations. Inclusion and participation can lead to employment (Blauwet et al., 2013), earning and material possession, which is also reported as a crucial coping resource in the current study. Lazarus and Folkman (1984) enlist material possessions as one of the important coping resources, which was also found in this study. However, there are fewer studies supporting material possession as a life-sustaining resource for persons with SCI, but there is evidence that employment and earning foster coping with loss and stressful conditions (Franzblau \& Chung, 2015).

Belief in God was found to be one of the coping resources used by persons with TSCI in this study. This type of coping has been reported in other studies (Babamohamadi, Negarandeh, \& Dehghan-Nayeri, 2011b; Kalpakjian et al., 2014). This could be due to the fact that, up until now, "human science" has failed to restore the function of spinal cord after complete damage. Knowing that science has failed in this aspect, an individual would find his or her self in a state of helplessness and hence turn to supernatural powers such as God in search for solace (Lankveld et al., 2011). However, it is not clearly stated in previous studies how faith in God helps in coping with adverse conditions, except in a few studies that associate this faith with hope, inner positivity and meaning in life (Bailey et al., 2015) as well as in Lazarus and Folkman (1984). Not knowing why persons with TSCI tend to cultivate faith in God or gods, some researchers have referred to this as "irrational belief" (Tse, 2007). Whether rational or irrational, this belief should be nurtured and be given its due chance during rehabilitation because it has been found to help individuals to find their inner self and a subjective sense of meaning (Littooij et al., 2016). Finding the inner self and sense of meaning has positive influence on coping and rehabilitation outcomes for persons with TSCI, regardless of setting. An almost indivisible connection has been drawn between faith, hope and acceptance (Babamohamadi, Negarandeh, \& Dehghan-Nayeri, 2011a). This relationship gives acceptance a crucial stance in promoting religious belief, which is one of the crucial coping resources.

When discussing mobility for persons with TSCI in rural settings, one must describe the wheelchair and accessibility of the environment (Oderud, 2014). Environment may accept (accessible) or reject (inaccessible) a wheelchair user. Inaccessible environment has been identified as one of the contributing factors to unemployment and other forms of participation restriction. In the same manner, appropriate mobility device (wheelchair) accepts the user, as opposed to an inappropriate one. It is the appropriateness of the wheelchair and the accessibility of the environment that determines the individual's mobility. A large part of Tanzania's rural areas is characterized by wheelchair-inaccessible roads, pathways to homes and inaccessible public buildings. Although solving the issue of environmental accessibility is broad and is policy related (Surona, Elsje, \& Marguerite, 2013), an appropriate wheelchair would still increase the chances of mobility and bring the population of persons with SCI closer to inclusion and participation in the community. However, according to WHO guidelines for provision of appropriate wheelchairs (page 11), an appropriate wheelchair is that which meets the user's needs and environmental conditions; provides proper fit and postural support; is safe and durable; is available in the user's country; and can be obtained and maintained, and its services sustained, in that country at the most economical and affordable price (WHO, ISPO, \& USAID, 2008a). There are various challenges in obtaining a wheelchairs in resource-constrained rural areas of Tanzania. Generally, they are hardly available, and the majority of persons with SCI cannot afford the few ones that are either imported or locally made (Oderud, 2014). As a result, most wheelchair users depend on donated wheelchairs, which are normally inappropriate for meeting the needs of the user and fail to overcome the environmental challenges.

This study adopted constructivist grounded theory by which the available data was approached inductively with the intention of understanding life with SCI in rural resource-constrained areas. This method was successful in guiding the researchers step by step into the formation of categories and the identification of the concept of acceptance as a theory that largely determines identification and utilization of the rest of the coping resources. Glaser and Strauss (1967) describe this achievement (theory development) as the ultimate goal of grounded theory. However, from the constructivist point of view, this is just one of the realities of life with SCI, and more than presented here can still be construed. This means the described theory stands to be tested, further described and even rejected with changing time and the context of occurrence of this experience because life is dynamic (Khan, 2014; Mills et al., 2006). Considering the classical constructivists' simultaneous data collection and analysis (Charmaz, 2008), this study falls short as data had been gathered few years back. However, the analysis followed such a path in that the first codes were reviewed several times in light of the memos and summaries to enable, subsequently, a more refined coding. Memos and interview summaries that were written immediately after the interviews were used as a "recall tool" to enable the researchers to reflect back to the times when the 
interviews took place.

\subsection{Ethical Consideration and Reflexivity}

This study followed all basic ethical rules for conducting a social study, ensuring such virtues as anonymity, confidentiality and voluntary inclusion. Official permission was obtained from the National Institute of Medical Research Tanzania in a letter dated $24^{\text {th }}$ January 2011.

For any qualitative study, it is crucial that the researcher describes the self and the chances that personal traits could have affected participants' responses or the conceptualization of the given information. The researcher who interviewed these participants is a physiotherapist in a hospital where the participants were admitted during their acute and sub-acute rehabilitation. The researcher had met some of them as outpatients and so he was not a complete stranger to any of them. This could have given the researcher greater rapport and made the interviewee more open during the interviews than there would be without this connection. He also had an added advantage because they referred to him as "their doctor".

However, there could be some few virtues that might have jeopardized the sharing of some information. The researcher was relatively young compared to the majority of the participants. Culturally, most elderly participants wouldn't share sensitive information such as marital conflicts or sexual life challenges in such a scenario. This would have been the same with women subjects who may not have felt comfortable sharing some "women-related" issues with a male researcher. However, the researcher feels that all participants trusted him as a health provider, and they shared with him almost all that needed to be heard.

\section{Conclusion}

Persons with traumatic spinal cord in rural settings face various challenges, including poverty, inaccessible environment and unavailability of basic health and rehabilitation services. However, some have managed to live long in these settings possibly due to their ability accept their conditions and to identify and utilization the available coping resources.

\section{Acknowledgements}

Acknowledgement is given to Health Serve Australia, which supported data collection for this study. We are indebted to all interviewees who shared facts about their lives to be used as data in this regard. We also appreciate the contribution of the Kilimanjaro Association for the Spinally Injured (KASI) in identifying key participants for the interview.

\section{Competing Interests Statement}

The authors declare that there are no competing or potential conflicts of interest regarding the publication of the paper.

\section{References}

Arya, S., Xue, S., Embuldeniya, A., Narammalage, H., da Silva, T., Williams, S., \& Ravindran, A. (2016). Coping strategies used by traumatic spinal cord injury patients in Sri Lanka: a focus group study. Disabil Rehabil, 38(20), 2008-2015. https://doi.org/10.3109/09638288.2015.1111433

Babamohamadi, H., Negarandeh, R., \& Dehghan-Nayeri, N. (2011a). Barriers to and facilitators of coping with spinal cord injury for Iranian patients: a qualitative study. Nurs Health Sci, 13(2), 207-215. https://doi.org/10.1111/j.1442-2018.2011.00602.x

Babamohamadi, H., Negarandeh, R., \& Dehghan-Nayeri, N. (2011b). Coping strategies used by people with spinal cord injury: A qualitative study. Spinal Cord, 49(7), 832-837. https://doi.org/10.1038/sc.2011.10

Bailey, A., Gammage, K. L., Ingen, C. v., \& Ditor, D. (2015). "It's all about acceptance": A qualitative study exploring a model of positive body image for people with spinal cord injury. Body Image, 15, 24-34. https://doi.org/10.1016/j.bodyim.2015.04.010

Bartel, P., Krebs, J., Wollner, J., Gocking, K., \& Pannek, J. (2014). Bladder stones in patients with spinal cord injury: a long-term study. Spinal Cord, 52(4), 295-297. https://doi.org/10.1038/sc.2014.1

Biering-Sorensen, F., Bickenbach, J. E., El Masry, W. S., Officer, A., \& von Groote, P. M. (2011). ISCoS-WHO collaboration. International Perspectives of Spinal Cord Injury (IPSCI) report. Spinal Cord, 49(6), 679-683. https://doi.org/10.1038/sc.2011.12

Blauwet, C., Sudhakar, S., Doherty, A. L., Garshick, E., Zafonte, R., \& Morse, L. R. (2013). Participation in organized sports is positively associated with employment in adults with spinal cord injury. Am J Phys Med 
Rehabil, 92(5), 393-401. https://doi.org/10.1097/PHM.0b013e3182876a5f

Burns, A. S., \& O'Connell, C. (2012). The challenge of spinal cord injury care in the developing world. J Spinal Cord Med, 35(1), 3-8. https://doi.org/10.1179/2045772311Y.0000000043

Charmaz, K. (2008). Grounded Theory as an Emergent Method. New York: The Guilford.

Chuang, C. H., Yang, Y. O., \& Kuo, L. T. (2015). Finding a Way to Cope: A Qualitative Study of the Experiences of Persons With Spinal Cord Injury. $J$ Neurosci Nurs, 47(6), 313-319. https://doi.org/10.1097/JNN.0000000000000169

Corbin, J., \& Strauss, A. (2008). Basics of Qualitative Research: Techniques and Procedures for Developing Grounded Theory (3rd ed.). Thousand Oaks CA: Sage. https://doi.org/10.4135/9781452230153

Davidson, J. E., \& Sternberg, R. J. (2003). The Psychology of Problem Solving (J. E. Davidson \& R. J. Sternberg Eds., 1st ed.). England: Cambridge University Press. https://doi.org/10.1017/CBO9780511615771

DeRoon-Cassini, T. A., de St Aubin, E., Valvano, A. K., Hastings, J., \& Brasel, K. J. (2013). Meaning-making appraisals relevant to adjustment for veterans with spinal cord injury. Psychol Serv, 10(2), 186-193. https://doi.org/10.1037/a0030963

Dibb, B., Ellis-Hill, C., Donovan-Hall, M., Burridge, J., \& Rushton, D. (2014). Exploring positive adjustment in people with spinal cord injury. $J$ Health Psychol, 19(8), 1043-1054. https://doi.org/10.1177/1359105313483158

Franzblau, L., \& Chung, K. C. (2015). Psychosocial outcomes and coping after complete avulsion traumatic brachial plexus injury. Disabil Rehabil, 37(2), 135-143. https://doi.org/10.3109/09638288.2014.911971

Glaser, B. G. (2002). Conceptualization: On Theory and Theorizing Using Grounded Theory. International Journal Qualitative Research, 1(2), 23-38. https://doi.org/10.1177/160940690200100203

Guilcher, S. J., Casciaro, T., Lemieux-Charles, L., Craven, C., McColl, M. A., \& Jaglal, S. B. (2012). Social networks and secondary health conditions: the critical secondary team for individuals with spinal cord injury. J Spinal Cord Med, 35(5), 330-342. https://doi.org/10.1179/2045772312Y.0000000035

Hwang, M., Zebracki, K., Chlan, K. M., \& Vogel, L. C. (2014). Longitudinal employment outcomes in adults with pediatric-onset spinal cord injury. Spinal Cord, 52(6), 477-482. https://doi.org/10.1038/sc.2014.32

Kalpakjian, C. Z., McCullumsmith, C. B., Fann, J. R., Richards, J. S., Stoelb, B. L., Heinemann, A. W., \& Bombardier, C. H. (2014). Post-traumatic growth following spinal cord injury. J Spinal Cord Med, 37(2), 218-225. https://doi.org/10.1179/2045772313Y.0000000169

Khan, S. N. (2014). Qualitative Research Method: Grounded Theory. International Journal of Business and Management, 9(11). https://doi.org/10.5539/ijbm.v9n11p224

Khanjani, M. S., Younesi, S. J., Khankeh, H. R., \& Azkhosh, M. (2017). Exploring Facilitators of Post-traumatic Growth in Patients with Spinal Cord Injury: A Qualitative Study. Electron Physician, 9(1), 3544-3553. https://doi.org/10.19082/3544

Knapp, M. S. (2016). The Practice of Designing Qualitative Research on Educational Leadership: Notes for Emerging Scholars and Practitioner-Scholars. Journal of Research on Leadership Education, 12(1), 26-50. https://doi.org/10.1177/1942775116647365

Kraft, R., \& Dorstyn, D. (2015). Psychosocial correlates of depression following spinal injury: A systematic review. J Spinal Cord Med, 38(5), 571-583. https://doi.org/10.1179/2045772314Y.0000000295

Lankveld, W., Diemen, T., \& Nes, I. (2011). Coping with spinal cord injury: Tenacious goal pursuit and flexible

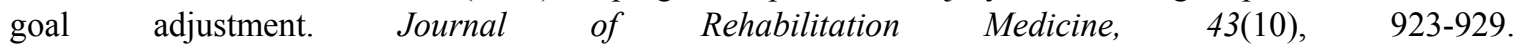
https://doi.org/10.2340/16501977-0870

Littooij, E., Leget, C. J., Stolwijk-Swuste, J. M., Doodeman, S., Widdershoven, G. A., \& Dekker, J. (2016). The importance of 'global meaning' for people rehabilitating from spinal cord injury. Spinal Cord, 54(11), 1047-1052. https://doi.org/10.1038/sc.2016.48

MacLachlan, M., \& Mannan, H. (2014). The World Report on Disability and its implications for rehabilitation psychology. Rehabil Psychol, 59(2), 117-124. https://doi.org/10.1037/a0036715

Meade, M. A., Reed, K. S., Saunders, L. L., \& Krause, J. S. (2015). It's All of the Above: Benefits of Working for Individuals with Spinal Cord Injury. Top Spinal Cord Inj Rehabil, 21(1), 1-9. 
https://doi.org/10.1310/sci2101-1

Middleton, J. W., Dayton, A., Walsh, J., Rutkowski, S. B., Leong, G., \& Duong, S. (2012). Life expectancy after spinal cord injury: a 50-year study. Spinal Cord, 50(11), 803-811. https://doi.org/10.1038/sc.2012.55

Mills, J., Bonner, A., \& Francis, K. (2006). Adopting a constructivist approach to grounded theory: implications for research design. Int J Nurs Pract, 12(1), 8-13. https://doi.org/10.1111/j.1440-172X.2006.00543.X

Muller, R., Peter, C., Cieza, A., \& Geyh, S. (2012). The role of social support and social skills in people with spinal cord injury--a systematic review of the literature. Spinal Cord, 50(2), 94-106. https://doi.org/10.1038/sc.2011.116

Muller, R., Peter, C., Cieza, A., Post, M. W., Van Leeuwen, C. M., Werner, C. S., . . Swi, S. C. I. S. G. (2015). Social skills: a resource for more social support, lower depression levels, higher quality of life, and participation in individuals with spinal cord injury? Arch Phys Med Rehabil, 96(3), 447-455. https://doi.org/10.1016/j.apmr.2014.09.006

Munce, S. E., Webster, F., Fehlings, M. G., Straus, S. E., Jang, E., \& Jaglal, S. B. (2014). Perceived facilitators and barriers to self-management in individuals with traumatic spinal cord injury: a qualitative descriptive study. BMC Neurology, 14(48), 1-12.

Mustonen, L. (2013). Open Code 4.03. Retrieved from http://www.phmed.umu.se/english/units/epidemiology/research/open-code/

Nutzi, M., Trezzini, B., Ronca, E., \& Schwegler, U. (2017). Key demands and characteristics of occupations performed by individuals with spinal cord injury living in Switzerland. Spinal Cord. https://doi.org/10.1038/sc.2017.84

Oderud, T. (2014). Surviving spinal cord injury in low income countries. Afr $J$ Disabil, 3(2), 80. https://doi.org/10.4102/ajod.v3i2.80

Reinhardt, J. D., Post, M. W., Fekete, C., Trezzini, B., Brinkhof, M. W., \& Swi, S. C. I. S. G. (2016). Labor Market Integration of People with Disabilities: Results from the Swiss Spinal Cord Injury Cohort Study. PLoS One, 11(11), e0166955. https://doi.org/10.1371/journal.pone.0166955

Ridler, C. (2017). Spinal cord injury: Insights into life expectancy after spinal cord injury. Nat Rev Neurol, 13(5), 258. https://doi.org/10.1038/nrneurol.2017.53

Salameh, A., Mohajer, M. A., \& Daroucihe, R. O. (2015). Prevention of urinary tract infections in patients with spinal cord injury. CMAJ, 187 (11), 807-811.

Simon, H. A. (1977). The Theory of Problem Solving Modes of Discovery (Vol. 54, pp. 261-277). Holland: Springer, Dordretcht.

Strauss, A., \& Corbin, J. (1998). Basics of Qualitative Research: Grounded Theory Procedures and Techniques (2nd ed.). London: Sage.

Surona, V., Elsje, S., \& Marguerite, S. (2013). Policy implementation in wheelchair service delivery in a rural South African setting. African Journal of Disability, 2(1). https://doi.org/10.4102/

Tse, L.-s. J. (2007). Irrational beliefs and psychosocial adjustment of people with spinal cord injuries (pp. 1-327).

van Leeuwen, C. M., Edelaar-Peeters, Y., Peter, C., Stiggelbout, A. M., \& Post, M. W. (2015). Psychological factors and mental health in persons with spinal cord injury: An exploration of change or stability. $J$ Rehabil Med, 47(6), 531-537. https://doi.org/10.2340/16501977-1953

WHO, ISPO, \& USAID. (2008a). APPROPRIATE WHEELCHAIR English Wheelchair Guidelines (J. Borg \& C. Khasnabis Eds.). Geneva: WHO Press.

WHO, ISPO, \& USAID. (2008b). Guidelines on the provision of Manual Wheelchairs in less resourced settings. Geneva, Switzerland: WHO Press.

Zinman, A., Digout, N., Bain, P., Haycock, S., Hebert, D., \& Hitzig, S. L. (2014). Evaluation of a community reintegration outpatient program service for community-dwelling persons with spinal cord injury. Rehabil Res Pract, 2014, 989025. https://doi.org/10.1155/2014/989025

Zsoldos, A., Satori, A., \& Zana, A. (2014). [Impact of animal-assisted intervention on rehabilitation of patients with spinal cord injury]. Orv Hetil, 155(39), 1549-1557. https://doi.org/10.1556/OH.2014.29977 


\section{Copyrights}

Copyright for this article is retained by the author(s), with first publication rights granted to the journal.

This is an open-access article distributed under the terms and conditions of the Creative Commons Attribution license (http://creativecommons.org/licenses/by/4.0/). 